\title{
A Simplified Model to Describe the Kinetic Behavior of Supercritical Fluid Extraction from a Rice Bran Oil Byproduct
}

\author{
Sus ana P. Jes us ${ }^{1}$, Maurício N. Calheiros ${ }^{2}$, Haiko Hense ${ }^{2}$, M. Angela A. Meire les ${ }^{1, *}$ \\ ${ }^{1}$ LASEFI/DEA (Department of Food Engineering), FEA (School of Food En gineering), UNICAMP (University of Campinas), Campinas, \\ 13083-862, Brazil \\ ${ }^{2}$ LATESC/EQA (Chemical and Food En gineering Department), UFSC (Federal University of Santa Catarina), Florianóp olis, 88040-900,
} Brazil

\begin{abstract}
The mathematical modeling of the overall extraction curve (OEC) was performed using experimental data of supercritical fluid extraction (SFE) from a byproduct of the rice bran oil (RBO) industry. The soapstock derived from the RBO deacidification process was used as raw material because it contains a significant amount of $\gamma$-ory zanol, which is a valuable natural antioxidant. The main goal of this work was to describe the OEC by a simplified model using the kinetic data obtained for the SFE from rice bran oil soapstock (RBOS). The global yield isotherms (GYI) were used to select the best operational conditions (temperature and pressure) based on the extraction yield and the $\gamma$-oryzanol content of the obtained extract. The OEC was fitted to four simplified models and the kinetic parameters which characterize the constant extraction rate (CER) were estimated. The highest values for the extraction yield $(12.5 \%, \mathrm{w} / \mathrm{w})$, the $\gamma$-oryzanol content $(16 \%, w / w)$, and the $\gamma$-oryzanol recovery rate $(55 \%, w / w)$ were found at $30 \mathrm{MPa} / 333 \mathrm{~K}$. The proposed spline model presented the best fit to experimental data and quantitatively described the OEC. The estimated time span of the CER period $\left(\mathrm{t}_{\text {CER }}\right)$ was $70 \mathrm{~min}$ and the corresponding solvent to feed $(\mathrm{S} / \mathrm{F})$ ratio and extraction yield were 23 and $9.4 \%$, respectively.
\end{abstract}

Keywords Overall Extraction Curve, Supercritical Carbon Dioxide, Spline Model, Rice Bran Oil Soapstock, Oryzanol

\section{Introduction}

Supercritical fluid extraction (SFE) is a versatile and environmentally friendly alternative to conventional extracti on processes. Carbon dioxide $\left(\mathrm{CO}_{2}\right)$ is the most used supercritical fluid because it has low critical temperature (304.2 K), mild critical pressure (7.38 MPa), and important characteristics such as non-toxic, non-flammable, non expensive, and readily available at good purity[1]. Some other well noticed advantages of the SFE are the easily solvent elimination, solvent recycling possibility, low energy consumption, adjustable solvent selectivity, and prevention of oxidation reactions $[2,3]$.

The investigation of the SFE process requires two types of experiments: the global yield isotherms (GYI), and the overall extraction curve (OEC). The GYI are performed in different conditions of temperature $(\mathrm{T})$ and pressure $(\mathrm{P})$ because both parameters are directly related to the adjustable selectivity of supercritical $\mathrm{CO}_{2}$. Therefore the GYI can be

* Corresponding author:

meireles@fea.unicamp.br (M. Angela A. Meireles)

Published online at http://journal.sapub.org/fph

Copyright (C) 2013 Scientific \& Academic Publishing. All Rights Reserved used to select the operational conditions of $\mathrm{T}$ and $\mathrm{P}$ based on the extraction yield and the chemical composition of the obtained extract[4]. After this selection the OEC must be determined because it brings information about the kinetic behaviorof the SFE process. A typical OEC presents three different regions [4 - 6]: (i) a constant extraction rate (CER) period where the solute contained at the surface of the particles is removed by convection; (ii) a falling extraction rate (FER) period where convection in the fluid phase and diffusion in the solid phase are both important mechanis ms; (iii) a diffusion-controlled (DC) period in which the mass transfer is controlled only by the diffusion mechanism.

The mathematical modeling of the OEC allows the determination of the time of extraction (cycle time), which is important for an optimal utilization of the industrial scale plant[7]. In order to achieve this, mathematical models must be evaluated with respect to their applicability in terms of process design. Many mathematical models have been developed to describe the OEC, from simple equations to very complex ones. Meireles[5] presented a simplified model in which the OEC was described by a family of two or three straight lines, where the first line represented the CER period. According to Pere ira and Meireles [8] $50-90 \%(w / w)$ of the total amount of extract can be obtained at the end of 
the CER period, what makes this step the most important one in terms of process design. Therefore, for many industrial applications, the extraction process ends shortly after the CER period because the best operational conditions will be those in which a high amount of extract is obtained in a relatively short process time[8]. The previous affirmation justifies why it is usual and important to determine some kinetic parameters which characterize the CER region of the OEC.

Researchers and consumers' interest in the rice bran oil (RBO) have been increasing due to its great potential as a nutraceutical food. The RBO health benefits are usually associated with natural antioxidant components such as tocopherols, tocotrienols and $\gamma$-oryzanol[ $[9,10]$. Attention is usually focused on $\gamma$-oryzanol (a group of ferulic acid esters of sterols and triterpene alcohols) since it has a powerful antioxidant action[11]. Improvement of the plasma lipid pattern, hypocholesterolemic activity, and treatment of inflammatory processes are some of the health-promoting effects attributed to $\gamma$-oryzanol[10, 12]. The antioxidant action has also been associated with the prevention of some cancers $[13,14]$.

In traditional chemical refining the deacidification is a process step in which the free fat acids are neutralized by addition of an alkali reagent, resulting in neutral oil plus soapstock as a byproduct. The $\gamma$-oryzanol content in the crude RBO varies in the range of $1.5-2.9 \%(\mathrm{w} / \mathrm{w})[15]$. During deacidification step, however, there is a significant decrease (up to $90 \%$ ) in the RBO $\gamma$-ory zanol content because it is transferred to the rice bran oil soapstock (RBOS) [10, $16]$.

According to Paucar-Menacho et a1.[15] the typical RBOS contains $1.2-3.6 \%(\mathrm{w} / \mathrm{w}$, dry basis) of $\gamma$-ory zanol. The RBOS has been mostly used to produce soap by detergent industries. Nevertheless, this byproduct has a remarkable potential o fbeing financially p rofitable since it could be used as a raw material for $\gamma$-oryzanol recovering processes[17]. The valuable antioxidant activity presented by $\gamma$-oryzanol makes it an interesting substance for wide application by food, cosmetic, and pharmaceutical industries.

Research works reporting the SFE from rice bran using supercritical $\mathrm{CO}_{2}$ as solvent have already been published, including comparisons between SFE and conventional hexane extraction as well as investigations to optimize the $\gamma$-oryzanol content in extracted oil[ $18-21]$. There are also reports about the application of conventional extraction techniques for recovering the $\gamma$-oryzanol available in the $\operatorname{RBOS}[22,23]$. However, as far as we know, there are yet no reports about the use of the RBOS as raw material for the supercritical $\mathrm{CO}_{2}$ extraction. The main goal of this work was to investigate the mathematical modeling of the OEC applying simplified models, as well as the determination of the kinetic parameters from the CER period. For that, we used experimental new data about the SFE using the RBOS as raw material. The GYI were evaluated in order to select the operational conditions ( $\mathrm{T}$ and $\mathrm{P}$ ) which maximize the $\gamma$-oryzanol recovery in the obtained extracts.

\section{Materials and Methods}

The experimental assays were performed in the Laboratory of Thermodynamics and Supercritical Technology (LATESC, EQA, UFSC, Florianópolis, Brazil). The details about the applied experimental methodology have been described in the sections 2.1 to 2.4 .

\subsection{Char acterization of the Raw Material}

The raw material was a RBOS obtained from IRGOVEL Ltd. (Pelotas, RS, Brazil). The RBOS initial mo isture content was determined gravimetrically using a drying oven at 378 $\mathrm{K}$ [24]. The $\gamma$-oryzanol content (OC) was quantified by high-performance liquid chro matography with UV detection (HPLC-UV), as detailed in section 2.4.

\subsection{Pretreatment of the Raw Material}

The RBOS pretreatment included three sequential steps: saponification, drying, and crushing. The first step was a saponification reaction, which was based on the methodology proposed by Rao and co-workers[25]. The RBOS saponification was carried out using sodium hydroxide $(\mathrm{NaOH})$ at controlled temperature $(363 \mathrm{~K})$ and constant stirring over a period of 1 hour. The proportion of reagents was 1:20 relating $\mathrm{NaOH}$ amount to RBOS dried matter content. The excess alkali was neutralized by sodium bicarbonate addition in order to adjust the $\mathrm{pH}$ between 9 and 10 , which is the optimu $\mathrm{pH}$ range for $\gamma$-ory zanol extraction from the RBOS[26].

The resultant soap was allowed to air-dry for 2 hours at room temperature. Then the soap was dried in an oven at 388 $\mathrm{K}$ for 4 hours. The dried soap was crushed and particles were fractionated in a vibratory sieve shaker (Bertel Metallurg ic Ind. Ltd., SP, Brazil). The obtained solid particles were used as the feed material for the SFE experiments.

\subsection{Supercritical Fluid Extraction}

The SFE equipment was a dynamic extraction unit developed by Zetzl and co-workers[27] at the TechnischeUniversität Hamburg-Harburg (Germany). The details about the unit design as well as the experimental procedures have already been well described in previous works [28, 29]. The extraction solvent was $\mathrm{CO}_{2} 99.9 \%$ pure delivered at pressure up to $6 \mathrm{MPa}$ (White Martins, Brazil). The extract was collected in the separator which was an amber g lass vial immersed in an ice bath at a mb ient pressure.

In the GYI assays the operational conditions of pressure and temperature varied according to a $3^{2}$ factorial design. The levels were: 10,20 , and $30 \mathrm{MPa}$ and 303,318 , and $333 \mathrm{~K}$. The mass of feed material (F), the total extraction time, the $\mathrm{CO}_{2}$ flow rate $\left(\mathrm{Q}_{\mathrm{CO} 2}\right)$, and the solvent to feed $(\mathrm{S} / \mathrm{F})$ ratio were: $30 \mathrm{~g}, 240 \mathrm{~min}, 1.67 \times 10^{-4} \mathrm{~kg} / \mathrm{s}$, and $\mathrm{S} / \mathrm{F}=80$, respectively. The assays were all performed in duplicates. In the kinetic experiments the extracted mass was collected and quantified in predetermined time intervals and the accumulated mass of extract was plotted as a function of the extraction time (t) to generate the OEC. The kinetic assays were performed using 
the following operational conditions: $\mathrm{F}=30 \mathrm{~g}, \mathrm{Q}_{\mathrm{CO} 2}=$ $1.67 \times 10^{-4} \mathrm{~kg} / \mathrm{s}, \mathrm{P}=30 \mathrm{MPa}$, and $\mathrm{T}=333 \mathrm{~K}$.

\subsection{Deter mination of the $\boldsymbol{\gamma}$-Oryzanol Content}

The $\gamma$-oryzanol quantification was performed by HPLC/UV according to Scavariello [30]. The analys is system was co mposed by: isocratic pump (Perkin Elmer Series 200); ultraviolet (UV)/visible detector (Perkin Elmer LC 290); column (Thermo Electron Corporation LICHROSORB RP $18 ; 4.6 \times 250 \mathrm{~mm}, 5 \mathrm{~mm}$ coupled to a C18-5 pre-colu mn). The UV detector was set at $315 \mathrm{~nm}$ and the mobile phase was composed by acetonitrile/methanol/isopropanol (50:45:5 by vol.) at a flow rate of $1.0 \mathrm{~mL} / \mathrm{min}$. The samples were diluted in hexane and a volume of $20 \mu \mathrm{L}$ was injected into the system.

\subsection{Calculation of the Extraction Yield and the $\gamma$-Oryzanol Recovery Rate}

The extraction yield $\left(\mathrm{X}_{0, \mathrm{~S} / \mathrm{F}}\right)$ of the GYI assays $(\mathrm{S} / \mathrm{F}=80)$ was calculated by the ratio between the mass of extracted matter and the mass of feed material (wet basis) used to fill the extraction cell. The $\gamma$-oryzanol recovery rate (ORR) was obtained by the ratio between the mass of $\gamma$-oryzanol in the extract and the mass of $\gamma$-oryzanol orig inally present in the raw material (RBOS) which was treated to produce the SFE feed material (according to the pretreatment described in section 2.2). Thus the ORR was calculated by Equation 1 using experimental data obtained for: $\mathrm{X}_{0, \mathrm{~S} / \mathrm{F}}(\%, \mathrm{w} / \mathrm{w})$, $\gamma$-oryzanol content in the extract $\left(\mathrm{OC}_{\mathrm{EXT}}\right)(\%, \mathrm{w} / \mathrm{w})$, $\gamma$-oryzanol content in the $\mathrm{RBOS}\left(\mathrm{OC}_{\mathrm{RBOS}}\right)(\%, \mathrm{w} / \mathrm{w})$, and pretreatment yield $\left(\mathrm{Y}_{\mathrm{PT}}\right)(\mathrm{w} / \mathrm{w})$. The pretreatment yield was defined as the ratio between the final mass of solid particles and the initial mass of crude raw material.

$$
\text { ORR (\%) }=\left(\frac{\mathrm{OC}_{\mathrm{EXT}} \mathrm{X}_{0, \mathrm{~S} / \mathrm{F}} \mathrm{Y}_{\mathrm{PT}}}{\mathrm{OC}_{\mathrm{RBOS}}}\right)
$$

\subsection{Mathe matical Modeling}

The extraction curve was obtained by plotting the accumulated mass of extract (or extraction yield) versus the extraction time. The OEC mathematical modeling was evaluated using the following models: empirical model presented by Esquívelet al.[31], diffusion model of Crank[32], logistic model presented by Martínez et al.[33], and spline model described by Meireles [5].

The empirical, diffusionand logistic models were fitted to experimental data using the software Mass Transfer (LATESC/EQA/UFSC, Florianópolis, Brazil)[34]. This software was developed in Delphi 7.0 using the maximum like lihood method to minimize the sum of the squares of the residues. The spline modeling was performed by fitting the experimental OEC to a spline containing three straight lines using the procedures PROC REG and PROC NLIN of the SAS software package (version 9.0, SAS Institute Inc., Cary, USA).

The adjustable parameters as well as the equations used in the mathematical modeling are detailed in Table 1 .
Table 1. Description of the equations used in the mathematical modeling of the overall extract ion curve (OEC)

\begin{tabular}{|c|c|}
\hline Model & Equation \\
\hline $\begin{array}{l}\text { Empirical } \\
{[31]}\end{array}$ & $\mathrm{m}_{\mathrm{EXT}}=\mathrm{x}_{0} \mathrm{~F}\left(\frac{\mathrm{t}}{\mathrm{C}_{1}+\mathrm{t}}\right)$ \\
\hline $\begin{array}{c}\text { Diffusion } \\
\text { [32] }\end{array}$ & $m_{\text {EXT }}=x_{0} F\left[1-\frac{6}{\pi^{2}} \sum_{n=1}^{\infty} \frac{1}{n^{2}} \exp \left(\frac{-n^{2} \pi^{2} D_{1} t}{r^{2}}\right)\right]$ \\
\hline $\begin{array}{c}\text { Logistic } \\
\text { [33] }\end{array}$ & $\mathrm{m}_{\mathrm{EXT}}=\frac{\mathrm{x}_{0} \mathrm{~F}}{\exp \left(\mathrm{C}_{2} \mathrm{t}_{\mathrm{m}}\right)}\left\{\frac{1+\exp \left(\mathrm{C}_{2} \mathrm{t}_{\mathrm{m}}\right)}{1+\exp \left[\mathrm{C}_{2}\left(\mathrm{t}_{\mathrm{m}}-\mathrm{t}\right)\right]}-1\right\}$ \\
\hline $\begin{array}{c}\text { Spline } \\
{[5]}\end{array}$ & $\begin{array}{l}\text { * when } \mathrm{t} \leq_{\mathrm{CER}} \text { : } \\
\qquad \mathrm{m}_{\mathrm{EXT}}=\mathrm{b}_{0}+\mathrm{b}_{1} \mathrm{t} \\
\text { * when } \mathrm{t}_{\mathrm{CER}}<\mathrm{t} \leq \mathrm{t}_{\mathrm{FER}} \\
\mathrm{m}_{\mathrm{EXT}}=\mathrm{b}_{0}+\mathrm{b}_{1} \mathrm{t}+\mathrm{b}_{2}\left(\mathrm{t}-\mathrm{t}_{\mathrm{CER}}\right) \\
\text { * when } \mathrm{t}>_{\mathrm{FER}} \\
\mathrm{m}_{\mathrm{EXT}}=\mathrm{b}_{0}+\mathrm{b}_{1} \mathrm{t}+\mathrm{b}_{2}\left(\mathrm{t}-\mathrm{t}_{\mathrm{CER}}\right)+\mathrm{b}_{3}\left(\mathrm{t}-\mathrm{t}_{\mathrm{FER}}\right)\end{array}$ \\
\hline \multicolumn{2}{|c|}{ 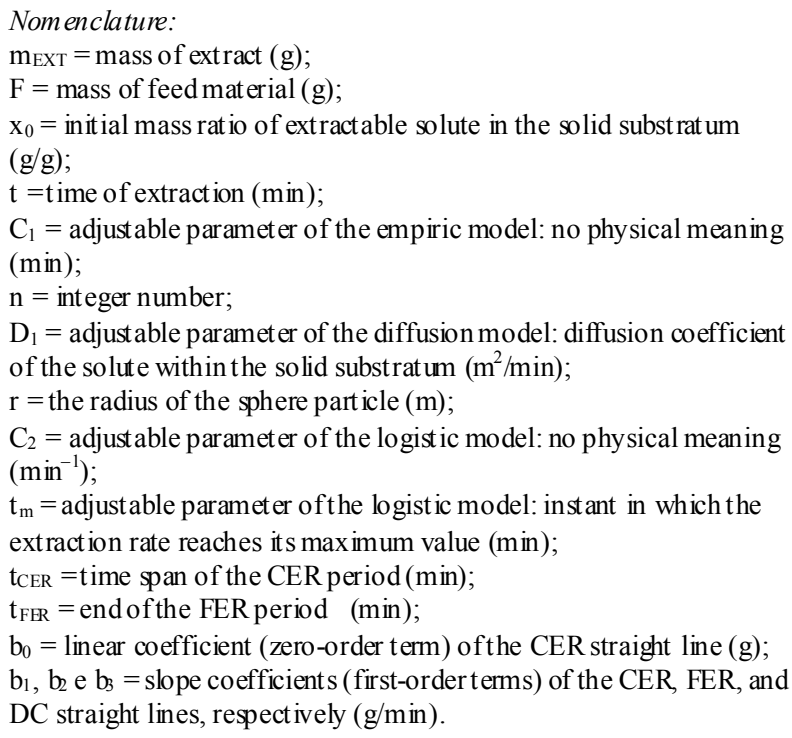 } \\
\hline
\end{tabular}

\subsection{Estimation of the Kinetic Parameters}

The experimental OEC was described by a family of three straight lines using a nonlinear fitting performed in the software SAS (as described in the section 2.6). The fitted lines were associated with three different mass transfer mechanis ms following the classic descriptions of the CER, FER and DC periods[6]. Thus the first, second, and third lines were respectively identified as the CER, FER, and DC regions. From the spline model the following para meters for the CER period were estimated: the time span of the CER period $\left(\mathrm{t}_{\mathrm{CER}}\right)$, the extraction rate for the CER period $\left(\mathrm{M}_{\mathrm{CER}}\right)$, the mass ratio of extract in the supercritical phase at the bed outlet $\left(\mathrm{Y}_{\mathrm{CER}}\right)$, the extraction yield of the CER period $\left(\mathrm{R}_{\mathrm{CER}}\right)$, and the solvent to feed mass ratio of the CER period ( $\left.\mathrm{S} / \mathrm{F}_{\mathrm{CER}}\right)$. The $t_{C E R}$ and $\mathrm{M}_{\mathrm{CER}}(\mathrm{kg}$ extract/s) are both adjustable parameters from the spline model $\left(t_{C E R}\right.$ and $b_{1}$, respectively, 
according to Table 1). The $\mathrm{Y}_{\mathrm{CER}}$ ( $\mathrm{kg}$ extract $/ \mathrm{kg} \mathrm{CO}_{2}$ ) was obtained by dividing $\mathrm{M}_{\mathrm{CER}}$ by the mean solvent flow rate $\left(\mathrm{Q}_{\mathrm{CO} 2}, \mathrm{~kg} \mathrm{CO} / \mathrm{s}\right)$. The parameters $\mathrm{R}_{\mathrm{CER}}(\%$, kg extract $/ \mathrm{kg}$ feed material) and $\mathrm{S} / \mathrm{F}_{\mathrm{CER}}(\mathrm{kg} \mathrm{CO} / \mathrm{kg}$ feed material) were calculated using modeled data $\left(\mathrm{m}_{\mathrm{EXT}}\right)$ from spline model.

\subsection{Statistical Analysis}

The statistical analysis of the experimental data was performed through a one-way Analysis of Variance (ANOVA) and Tukey test using the software STATISTICA for W indows (version 7.0, Statsoft Inc., USA). A calculated $\mathrm{p}$-value $<0.05$ was considered to be statistically significant.

\section{Results and Discussion}

\subsection{Char acterization of the Raw Material}

The RBOS characterization analyses resulted in a mo isture content of $45 \pm 1 \%(\mathrm{w} / \mathrm{w})$ and a $\gamma$-oryzanol content of $2.7 \pm 0.1 \%$ (w/w, dry basis). The determined RBOS mo isture content is lower than the ones reported by Narayan et al.[17] ( $65-70 \%$, w/w) and by Kaewboonnum et al.[22] $(57 \%, w / w)$. Such differences in the mo isture content are understandable since the RBOS composition depends on operational parameters of the RBO refining process, which usually differ from one industry to another. Some variations in the deacidification step, such as centrifugation time and amount of water and alkali added in the process, as well as rice bran initial composition, have direct influence on the RBOS composition. The obtained $\gamma$-oryzanol content $(2.7 \pm 0.1 \%$, w/w, dry basis $)$ is in accordance with the range $(1.2-3.6 \%, \mathrm{w} / \mathrm{w}$, dry basis $)$ reported by Paucar-Menacho et al.[15].

\subsection{Pretreatment of the Raw Material}

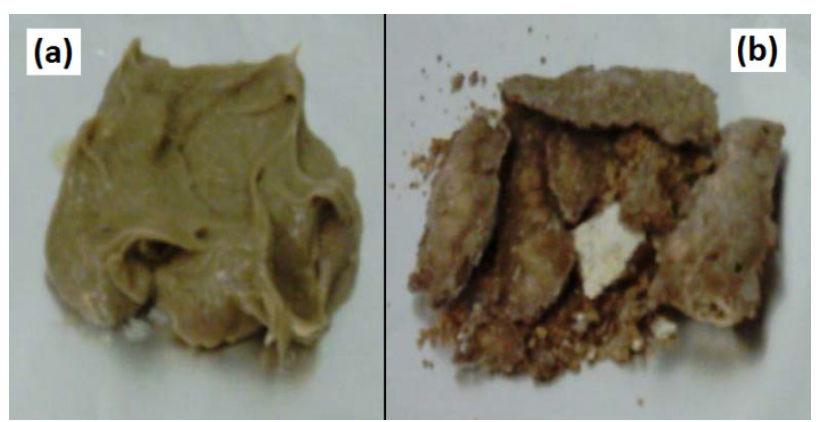

Figure 1. Raw material pretreatment: (a) crude rice bran oil soapstock (RBOS); (b) RBOS after saponification and drying steps

The RBOS received from the RBO industry was the crude raw material (Figure 1a) which was pretreated in order to obtain the feed material used in the SFE. The pretreatment was conducted in three steps: saponification, drying, and crushing. The material presented in Figure $1 \mathrm{~b}$ was the RBOS after the saponification reaction and the drying process. This material was then crushed and the obtained solid particles were fed into the fixed extraction bed.

The solid particles moisture content was less than $3 \%$ $(\mathrm{w} / \mathrm{w})$ and the mean particle diameter was $2.4 \times 10^{-4} \mathrm{~m}$. The pretreatment yield (as previously defined in section 2.5 ) was equal to $0.41 \mathrm{~g}$ of solid particles/g of RBOS.

\subsection{Extraction Yield, $\gamma$-Oryzanol Content, and $\gamma$-Oryzanol Recovery Rate}

The interactions between the solvent and the various solutes present in the solid substratum are fundamental to understand the SFE process. However, the solid substratum is a complex multicomponent system and very little information is known about these interactions. The extension of these interactions can be measured through the determination of the solubility of the system (solid substratum $+\mathrm{CO}_{2}$ ) or through the results of the GYI experiments[35].

The results of the GYI assays are presented (Table 2) in terms of extraction y ield, $\gamma$-ory zanol content and $\gamma$-oryzanol recovery rate. Taking into account an isothermal condition a rising operational pressure resulted in the increase of both the extraction yield and the $\gamma$-ory zanol content. This effect can be attributed to the increase in $\mathrm{CO}_{2}$ density and therefore the enhancement in the solvation power.

Table 2. Results of the global yield isotherms (GYI) assays: extraction yield $\left(\mathrm{X}_{0, \mathrm{~S} / \mathrm{F}}\right), \gamma$-oryzanol content (OC) and $\gamma$-oryzanol recovery rate (ORR)

\begin{tabular}{|c|c|c|c|c|c|}
\hline $\begin{array}{c}\mathrm{P} \\
(\mathrm{MPa})\end{array}$ & $\mathrm{T}(\mathrm{K})$ & $\begin{array}{c}\rho \mathrm{CO}_{2}{ }^{(\mathrm{I})} \\
\left(\mathrm{kg} / \mathrm{m}^{3}\right)\end{array}$ & $\begin{array}{c}\mathrm{X}_{0, \mathrm{~S} / \mathrm{F}} \\
(\%, \mathrm{w} / \mathrm{w})\end{array}$ & $\begin{array}{c}\text { OC } \\
(\%, \mathrm{w} / \mathrm{w})\end{array}$ & $\begin{array}{c}\text { ORR } \\
(\%, \mathrm{w} / \mathrm{w})\end{array}$ \\
\hline 10 & 303 & 773 & $6.1^{\mathrm{a}} \pm 0.3$ & 0.5 & 0.8 \\
\hline 10 & 318 & 503 & $2.2^{\mathrm{b}} \pm 0.2$ & 0.3 & 0.2 \\
\hline 10 & 333 & 291 & $0.22^{\mathrm{c}} \pm 0.04$ & 0.03 & 0.0 \\
\hline 20 & 303 & 891 & $10.4^{\mathrm{d}, \mathrm{e}} \pm 0.2$ & 3.4 & 10 \\
\hline 20 & 318 & 814 & $9.7^{\mathrm{d}} \pm 0.1$ & 2.8 & 7.4 \\
\hline 20 & 333 & 725 & $5.3^{\mathrm{a}} \pm 0.1$ & 2.4 & 3.5 \\
\hline 30 & 303 & 949 & $10.6^{\mathrm{d}, \mathrm{e}} \pm 0.9$ & 11.8 & 34 \\
\hline 30 & 318 & 891 & $11.1^{\mathrm{e}} \pm 0.4$ & 13.5 & 41 \\
\hline 30 & 333 & 830 & $12.5^{\mathrm{f}} \pm 0.5$ & 16.0 & 55 \\
\hline
\end{tabular}

(I) Carbon dioxide density[36]

(II) Equal letters indicate no statistically significant difference

The effect of the process temperature in the SFE is typically more complex[37, 38] and can be better understood through the analysis of the GYI presented in Figure 2, where a crossover point (near $27 \mathrm{MPa}$ ) can be clearly observed. At 10 and $20 \mathrm{MPa}$ the rising temperature produced a decrease in the extraction yields as well as in the $\gamma$-oryzanol content of the obtained extracts. This effect is associated with the significant reduction in the solvent density and therefore it is possible to conclude that below crossover pressure the density effect was the dominant mechanis $m$ in the SFE process. At $30 \mathrm{MPa}$, on the other hand, an increase in the process temperature resulted in the enhancement ofthe extraction yield and the $\gamma$-oryzanol content. This behavior can be explained because in the highest pressure the $\mathrm{CO}_{2}$ density changed slightly with temperature, and as a consequence the solute vapor pressure was the dominant mechanis $m$ affecting the extraction process. 


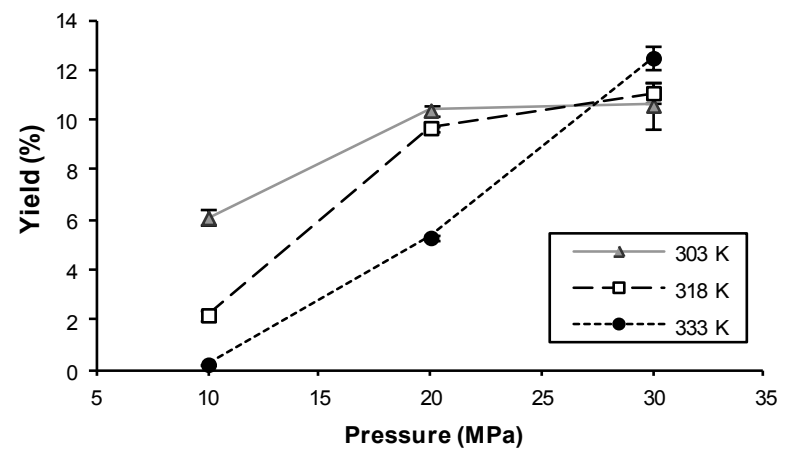

Figure 2. Global yield isotherms $(303,318$, and $333 \mathrm{~K})$ obtained in the SFE process (the experimental points are connected to evidence the isotherms crossover)

Analogous pressure and temperature effects in the GYI results, as well as the presence of a crossover region, have already been noticed by many authors studying a wide range of raw materials $[4,29,35,38-39]$. It is actually well established in the specific literature that both pressure and temperature are key variables in the SFE process.

The highest OC and ORR values were found at 30 $\mathrm{MPa} / 333 \mathrm{~K}$. The maximum OC $(16 \%, \mathrm{w} / \mathrm{w})$ obtained in this work was lower than the ones reported by Kumar and co-workers[23] for conventional extraction using various organic solvents. These authors studied the recovery of $\gamma$-oryzanol from RBOS through Soxhlet extraction and found a maximum OC $(25 \%, w / w)$ when using ethyl acetate as solvent. Higher values for the OC (up to $90 \%$, $\mathrm{w} / \mathrm{w})$ can be obtained when the extract is further purified to achieve higher $\gamma$-oryzanol purity. Processes for $\gamma$-oryzanol purification usually involve sequential steps including fractional precipitation, crystallization, and/or separation by chromatographic colu mn $[22,25]$.

The maximum ORR $(55 \%, \mathrm{w} / \mathrm{w})$ is higher than the value $(31 \%, w / w)$ reported by Jesus et al.[40] in a previous work in which a different RBO byproduct was used as feed material for the SFE process. The obtained ORR could not be appropriately compared with some results from other works because it seems that each author calculates the $\gamma$-oryzanol recovery based on specific considerations which are usually different from one research group to another. In the present work we defined the ORR by Equation 1, however this kind of information was not found in other authors' works and therefore no additional comparisons were possible.

\subsection{Mathe matical Modeling and Kinetic Parameters}

The experimental and modeled curves are illustrated in Figure 3. The adjustable parameters and the mean square error (MSE) calculated for the applied models are presented in Table 3.

The analysis of the lowest MSE values, as well as the visual observation of Figure 3, indicated that both the spline[5] and logistic[33] models could quantitatively describe the OEC. The distribution of the residuals (Figure 4) confirmed the good fits presented by spline and logistic models.

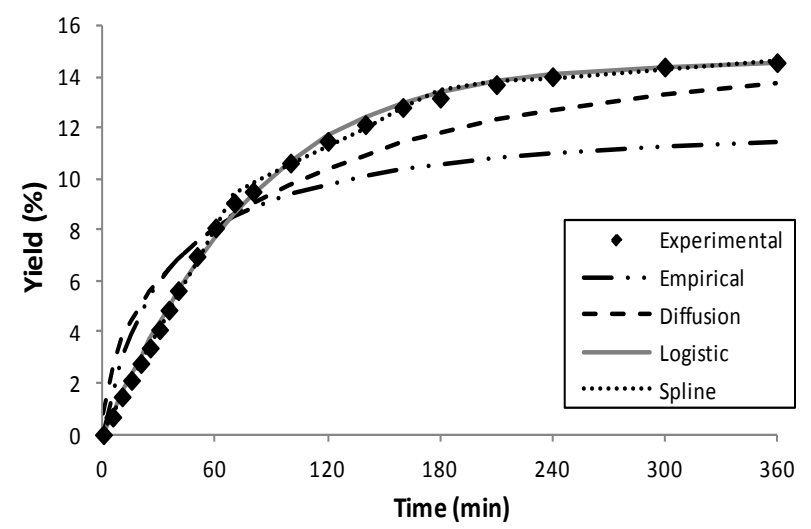

Figure 3. Experimental data $(30 \mathrm{MPa} / 333 \mathrm{~K})$ and modeled extraction curves obtained by empirical[31], diffusion[32], logistic[33], and spline[5] models

The empirical[31] and diffusion[32] models did not present good agreements with experimental data and so could not be used to describe quantitatively the OEC. This performance was already expected taking into account the specific characteristics of these models. Therefore both were applied in this work only for comparison purposes. The empirical model is described by a very simple equation (Table 1) which has just one adjustable parameter and no physical meaning. The diffusion model has some relation with the mass transfer phenomenon but it considers only the diffusion mechanism since the mass balance is applied to the solid phase while fluid phase is neglected. The observation of the experimental curve shape already indicated that the diffusion model would not be adequate since the convective mechanis $m$ should not be neglected in the extraction process.

Table 3. Mathematical modeling of the overall extraction curve and kinet ic parameters of the constant extraction rate (CER) period

\begin{tabular}{|c|c|c|}
\hline Model & Adjustable parameter ${ }^{(\mathbb{l})}$ & $\operatorname{MSE}^{(I I)}$ \\
\hline Empirical[31] & $\mathrm{C}_{1}=32.8 \mathrm{~min}$ & 0.332 \\
\hline Diffusion[32] & $\mathrm{D}_{1}=9.49 \times 10^{-12}\left(\mathrm{~m}^{2} / \mathrm{min}\right)$ & 0.192 \\
\hline Logistic[33] & $\begin{aligned} \mathrm{C}_{2} & =0.0159\left(\mathrm{~min}^{-1}\right) \\
\mathrm{t}_{\mathrm{m}} & =-54.6(\mathrm{~min})\end{aligned}$ & 0.004 \\
\hline Spline[5] & $\begin{array}{c}\mathrm{b}_{0}(\mathrm{~g})=0.0386 \\
\mathrm{~b}_{1}(\mathrm{~g} / \mathrm{min})=0.0398 \\
\mathrm{~b}_{2}(\mathrm{~g} / \mathrm{min})=-0.0288 \\
\mathrm{~b}_{3}(\mathrm{~g} / \min )=-0.0092 \\
\mathrm{t}_{\mathrm{CER}}(\min )=70 \\
\mathrm{t}_{\mathrm{FER}}(\min )=186\end{array}$ & 0.002 \\
\hline \multicolumn{2}{|c|}{ Kinet ic parameter } & $\begin{array}{l}\text { Estimated } \\
\text { value }\end{array}$ \\
\hline \multicolumn{2}{|c|}{$\mathrm{M}_{\mathrm{CER}} \times 10^{7}(\mathrm{~kg}$ extract $/ \mathrm{s})$} & 6.63 \\
\hline \multicolumn{2}{|c|}{$\mathrm{Y}_{\mathrm{CER}} \times 10^{3}(\mathrm{~kg}$ extract $/ \mathrm{kg} \mathrm{CO})$} & 3.98 \\
\hline \multicolumn{2}{|c|}{$\mathrm{R}_{\text {CER }}(\%, \mathrm{~kg}$ extract $/ \mathrm{kg}$ feed $)$} & 9.4 \\
\hline \multicolumn{2}{|c|}{$[\mathrm{S} / \mathrm{F}]_{\text {CER }}\left(\mathrm{kg} \mathrm{CO}{ }_{2} / \mathrm{kg}\right.$ feed $)$} & 23 \\
\hline
\end{tabular}

(I) The description of the adjustable param eters is presented in Table 1 (II) Mean Square Error (MSE) 


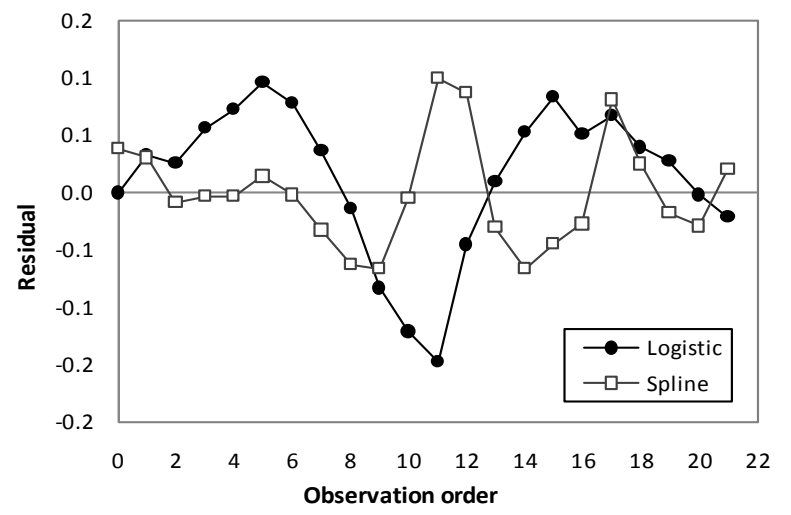

Figure 4. The distribution of the residuals obtained from mathematical modeling using logistic[33] and spline[5] models

According to Martínez et al.[33] the logistic model was developed from the differential mass balance applied inside the extraction bed for solid and fluid phases. The particularity of the logistic model was the definition of the interfacial mass-transfer term, which was described by one of the solutions from the logistic equation. The logistic model has two adjustable parameters named here (Table 1) as $\mathrm{C}_{2}$ and $\mathrm{t}_{\mathrm{m}}$. No physical mean ing was attributed to the first one $\left(\mathrm{C}_{2}\right)$, while the second one $\left(\mathrm{t}_{\mathrm{m}}\right)$ was described as the time in which the extraction rate reaches its maximum value[33]. However, when applying this model to usual OEC shapes, many authors [3, 38 - 40] have obtained negative values for $t_{m}$ and therefore no physical meaning could be associated to this parameter. Although logistic model provided a good quantitative description of the OEC, the absence of physical meaning turned it into an empirical model. Therefore the logistic model adjustable para meters would not be applicable in terms of process design and scale up.

The spline model presented the lowest MSE value and described very well the OEC quantitative behavior. Besides that, yet being a very simple model in terms of mathematical complexity, the spline model could also be related to the mass transfer phenomena since the experimental and modeled curves showed the distinctive three regions: CER, FER, and DC. The description of the CER period by a straight line was used to estimate the kinetic parameters which are presented in Table 3 . The $\mathrm{R}_{\mathrm{CER}}$ value represented $64 \%$ of the total extraction y ield $(14.7 \%)$ obtained at the end of the OEC. This is in accordance with the range (50-90\%) mentioned by Pereira and Meireles[8] when justify ing the relevance of the CER period.

The values of $t_{C E R}$ and $R_{C E R}$ roughly represent the minimum time a SFE cycle should last and the minimum extraction yield expected at a given process condition ( $T, P$, $\mathrm{Q}_{\mathrm{CO} 2}$, and solid substratum pretreat ment)[5]. The parameters $t_{C E R},(S / F)_{C E R}$, and $R_{C E R}$ can be used in preliminary studies of the process design by applying the scale up criterion proposed by Prado and co-workers[41 - 42]. This criterion basically consists in maintaining constant the solvent to feed $(\mathrm{S} / \mathrm{F})$ ratio and also the process time which was necessary to achieve the respective $\mathrm{S} / \mathrm{F}$ value. After the scale-up prediction is done the economical viability of the process can be investigated by making the estimation of the cost of manufacturing (COM) as described by Rosa and Meireles[43].

According to Leal[44], the intersection between the lines CER and DC defines an additional para meter of time, which is named as $t_{\text {CER2 }}$. This parameter can also be used as a good estimation of the process time for preliminary studies about the COM prediction[4]. The calculated value of the parameter $\mathrm{t}_{\mathrm{CER} 2}$ was $98 \mathrm{~min}$, and the mass of extract obtained at this point was $71 \%$ of the total mass recovered at the final time of extraction. Both the parameters $t_{\mathrm{CER}}$ and $\mathrm{t}_{\mathrm{CER} 2}$ can be used as an initial estimative of the cycle time when performing exp loratory investigations about the economical viability of the SFE process.

The specific literature about the SFE presents several more complex mathematical models to describe the OEC. The more accurate models can provide a more reliable description of the mass transfer phenomena in the fixed bed extractor. However, the application of these models also requires some additional data which not always are available to the investigated system. One example is the model described by Sovová[6], which requires information about the true density of the solid particles and also about the solubility of the pseudo-binary system formed by extract (a multico mponent mixture of solutes) $+\mathrm{CO}_{2}$. The data about solubility is not always available and the experimental determination is not an easy or quick procedure. Therefore, when considering the above mentioned scenario, it is possible to say that one advantage of the spline model is that only the kinetic data of the SFE is enough to perform the mathematical modeling of the OEC.

\section{Conclusions}

The high $\gamma$-oryzanol content $(2.7 \%, \mathrm{w} / \mathrm{w}$, dry basis $)$ detected in the RBOS confirmed its potential as a raw material for $\gamma$-ory zanol recovering processes. The analysis of the GYI results (Table 2) indicated that the best operational condition was found at $30 \mathrm{MPa} / 333 \mathrm{~K}$. The spline model presented the best fit to the OEC and the values calculated for the parameters $t_{\mathrm{CER}}$ and $t_{\mathrm{FER}}$ were, respectively, 70 and $186 \mathrm{~min}$. At the end of the CER and FER periods the extracted mass was $64 \%$ and $93 \%$ of the total mass obtained at the final time of extraction.The spline model presents a very low mathematical complexity, and despite that can describe very well the OEC when only kinetic data about the investigated system are readily available.

\section{ACKNOWLEDGEMENTS}

The authors thank CNPq (477986/2007-2) for the financial support of the experimental work and IRGOVEL Ltd. (Pelotas, RS, Brazil)for the donation of the raw material. Susana P. Jesus thanks CNPq (141828/2010-2) for the doctorate fellowship. 


\section{REFERENCES}

[1] Paulo T.V. Rosa, M.Angela A. Meireles, "Fundamentals of supercritical extraction from solid matrices", pp. 272-288, in: M.A.A. Meireles (Ed.), "Extracting Bioactive Compounds for Food Products: Theory and Application", CRC Press - Taylor \&Francis Group, USA, 2009.

[2] Leandro Danielski,CarstenZetzl, HaikoHense,Gerd Brunner, "A process line for the production of raffinated rice oil from rice bran", Elsevier, The Journal of Supercritical Fluids, vol. 34, pp. 133-141, 2005.

[3] NatáliaMezzomo, Julian Martínez,Sandra R. S. Ferreira, "Supercritical fluid extraction of peach (Prunuspersica) almond oil: kinetics, mathematical modeling and scale-up", Elsevier, The Journal of Supercritical Fluids, vol. 51, pp. 10-16, 2009.

[4] Carolina L. C. Albuquerque, M. Angela. A. Meireles, "Defatting of annatto seeds using supercritical carbon dioxide as a pretreatment for the production of bixin: Experimental, modeling and economic evaluation of the process", Elsevier, The Journal of Sup ercritical Fluids, vol.66, pp. 86-94, 2012.

[5] M. Angela. A. Meireles, "Extraction of bioactive compounds from Latin American plants", pp. 243-274, in: J. Martinez (Ed.) "Supercritical Fluid Extraction of Nutraceuticals and Bioactive Compounds", CRC Press - Tay lor \& Francis Group, USA, 2008.

[6] Helena Sovová,"Rate of the vegetable oil extraction with supercritical $\mathrm{CO}_{2}-\mathrm{I}$. Modeling of extraction curves."Elsevier, Chemical Engineering Science, vol. 49, no. 3, pp. 409-414, 1994.

[7] Gerd Brunner, "Gas extraction: an introduction to fundament als of supercritical fluid and the applications to separation processes”, 1st ed., Steinkopff, Germany, 1994.

[8] Camila G. Pereira, M. Angela A Meireles, "Supercritical Fluid Extraction of Bioactive Compounds: Fundamentals, Applications and Economic Perspectives”. Springer, Food and Bioprocess Technology,vol. 3, pp. 340-372, 2010.

[9] F. T. Orthoefer, "Rice bran oil: healthy lipid source", IFT, Food Technology, vol. 50, pp. 62-64, 1996.

[10] Christianne E. C. Rodrigues, Márcia M. Onoyama, Antonio J. A. Meirelles, "Optimization of the rice bran oil deacidification process by liquid-liquid extraction", Elsevier, Journal of Food Engin eering, vol. 73, pp. 370-378, 2006.

[11] Remo Bucci, Andrea D. Magrì, Antonio L. Magrì, Federico Marini,"Comparison of three spectrophotometric methods for the determination of $\gamma$-oryzanol in rice bran oil", Springer, Analytical and Bioanalytical Chemistry, vol. 375, pp. 1254-1259, 2003.

[12] Claudia Juliano, Massimo Cossu, Maria C. Alamanni, LuisellaPiu, "Antioxidant activity of gamma-oryzanol: mechanism of action and its effect on oxidative stability of pharmaceutical oils", Elsevier, International Journal of Pharmaceutics, vol. 299, pp. 146-154, 2005.

[13] Carrie K. L. Kong, W. S. Lam, Lawrence C. M. Chiu, Vincent E. C.Ooi, Samuel S. M. Sun, Yum-Shing Wong, "A rice bran polyphenol, cycloartenylferulate, elicits apoptosis in human colorectal adenocarcinoma SW480 and sensitizes metastatic SW620 cells to TRAIL-induced apoptosis", Elsevier, Biochemical Pharmacology, vol. 77, no. 9, pp. 1487-1496, 2009.

[14] V. Van Hoed, G. Depaemelaere, J. Vila Ayala, P. Santiwattana, R. Verhé, W. De Greyt,"Influence of chemical refining on the major and minor components of rice bran oil", AOCS Press, Journal of the American Oil Chemists Society, vol. 83, no. 4, pp. 315-321, 2006.

[15] Luz M. Paucar-Menacho, Leomar H. Silva, Anderson S. Sant'ana, Lireny A. G. Gonçalves, "Refiningofricebranoil (Oryza sativa L.) to preserve $\gamma$-oryzanol",SBCTA, Ciência e Tecnologia de Alimentos, vol. 27, 45-53, 2007.

[16] L. Rajam, D. R. Soban Kumar, A. Sundaresan, C. Arumughan,"A novel process for physically refining rice bran oil through simultaneous degumming and dewaxing", Springer, Journal of the American Oil Chemists' Society, vol. 82, no. 3, pp.213-220, 2005.

[17] A. V. Narayan, R. S. Barhate, and K. S. M. S. Raghavarao, "Extraction and purification of oryzanol from rice bran oil and rice bran oil soapstock",Springer, Journal of the American Oil Chemists' Society, vol. 83, no.8, pp. 663-670, 2006.

[18] C. Balachandran, P. N. Mayamol, Shiny Thomas, DivyaSukumar, A. Sundaresan, "An ecofriendly approach to process rice bran for high quality rice bran oil using supercritical carbon dioxide for nutraceutical applications", Elsevier, Bioresource Technology, vol. 99, pp. 2905-2912, 2008.

[19] M.S. Kuk, M.K. Dowd,"Supercritical $\mathrm{CO}_{2}$ extraction of rice bran", Springer, Journal of the American Oil Chemists' Society, vol. 75, no. 5, pp. 623-628, 1998.

[20] Giuseppe Perretti, Enrico Miniati, Luigi Montanari, Paolo Fantozzi, "Improving the value of rice by-products by SFE", Elsevier, The Journal of Supercritical Fluids, vol. 26, pp. 63-67, 2003.

[21] ZhiminXu, J. Samuel Godber,"Comparison of supercritical fluid and solvent extraction methods in extracting $\gamma$-oryzanol from rice bran", Springer, Journal of the American Oil Chemists' Society, vol. 77, no. 5, pp. 547-551, 2000.

[22] Pitchanan Kaewboonnum, Janya Vechpanich , Pravit Santiwattana, ArtiwanShotipruk " " $\gamma$-oryzanol recovery from rice bran oil soapstock", Taylor \& Francis Group, Separation Science and Technology, vol. 45, no. 9, 1186-1195, 2010.

[23] Raj R. Kumar, Purnima K. Tiku, VishveshwaraiahPrakash, "Preferential extractability of $\gamma$-oryzanol from dried soapstock using different solvents",Society of Chemical Industry, Journal of the Science of Food and Agriculture, vol. 89, pp. 195-200, 2009.

[24] AOAC, "Official Methods of Analysis", 11th ed., Association of Official Analytical Chemists, USA, 1990.

[25] K. V. S. A. Rao, B. V. S. K. Rao, T.N.B. Kaimal,“Process for the isolation of oryzanols from rice bran oil soapstock", US Patent No 6410762, 2002.

[26] G. S. Seetharamaiah, J. V. Prabhakar,"Oryzanol content of Indian rice bran oil and its extraction from soapstock", Springer, Journal of Food Science and Technology, vol. 23, no.5, pp.270-273, 1986. 
[27] CarstenZetzl, Gerd Brunner,M. Angela A. Meireles, "Standardized low cost SFE units for university education and comparative research", in Proceedings of the 6th International Symposium on Supercritical Fluids, Versailles, France, ISBN 2-905-267-37-02, 2003.

[28] Aziza K. Genena, HaikoHense, ArturSmânia Jr., Simone M. Souza,"Rosemary (Rosmarinusofficinalis) - a study of the composition, antioxidant and antimicrobial activities of extracts obtained with supercritical carbon dioxide", SBCT A,Ciência e Tecnologia de Alimentos, vol. 28, no. 2,pp. 463-469, 2008.

[29] Eliane M. Z. Michielin, Louisiane F. V. Bresciani, Leandro Danielski, Rosendo A. Yunes, Sandra R. S. Ferreira, "Composition profile of horsetail (Equisetum giganteum L.) oleoresin: comparing SFE and organic solvents extraction", Elsevier, The Journal of Supercritical Fluids, vol. 33, pp. 131-138, 2005.

[30] Eliete M. S. Scavariello,"Modificação química e enzimática da borra de neutralização do óleo de farelo de arroz". Ph.D. Thesis, University of Campinas, Brazil, 2002.

[31] M. M. Esquível, M. G. Bernardo-Gil, M. B. King "Mathematical models for supercritical extraction of olive husk oil", Elsevier, The Journal of Supercritical Fluids, vol. 16, pp. 43-58, 1999.

[32] J. Crank, "The Mathematics of Diffusion", 2nd ed., Claredon Press, United Kingdom, 1975.

[33] Julian Martínez, Alcilene R. Monteiro, Paulo T. V. Rosa, Márcia O. M. Marques, M. Angela A. Meireles, "Multicomp onent model to describe extraction of ginger oleor esin with supercritical carbon dioxide",ACS Publications, Industrial and Engineering Chemistry Research, vol. 42, 1057-1063, 2003.

[34] Jeferson Correia, Eliane M.Z. Michielin, Sandra R.S. Ferreira, "Estudo de modelos de transferência de massa para processos de extração supercritica", Scientificinitiationreport (PIBIC CNPQ), Federal University of Santa Catarina, Brazil, 2006.

[35] Raul N. Carvalho Jr.,Lucinewton S. Moura, Paulo T. V. Rosa, M. Angela.A. Meireles, "Sup ercritical fluid extraction from rosemary (Rosmarinusofficinalis): Kinetic data, extract's global yield, composition, and antioxidant activity", Elsevier,The Journal of Supercritical Fluids, vol. 35, pp. 197-204, 2005.

[36] E.W. Lemmon, M.O. McLinden, D.G. Friend, "Thermophysi cal Properties of Fluid Systems", in NIST Chemistry
WebBook, NIST Standard Reference Database Number 69, Eds. P.J. Linstrom and W.G. Mallard, National Institute of Standards and Technology, USA, Online Available: http://webbook.nist.gov.

[37] Leandro Danielski, Luanda M. A. S. Campos, Louisiane F. V. Bresciani, HaikoHense, Rosendo A. Yunes, Sandra R.S. Ferreira,"Marigold (Calendula officinalis L.) oleoresin: solubility in $\mathrm{SC}-\mathrm{CO}_{2}$ and composition profile",Elsevier, Chemical Engineering and Processing, vol. 46, pp. 99-106, 2007.

[38] Cíntia S. G. Kitzberger, Rodrigo H. Lomonaco, Eliane M. Z. Michielin, Leandro Danielski, JefersonCorreia, Sandra R.S. Ferreira,"Supercritical fluid extraction of shiitake oil: curve modeling and extract composition",Elsevier, Journal of Food Engineering, vol. 90, pp. 35-43, 2009.

[39] Luanda M. A. S. Campos, Eliane M. Z. Michielin, Leandro Danielski, Sandra R. S. Ferreira,"Experimental data and modeling the supercritical fluid extraction of marigold (Calendula officinalis) oleoresin", Elsevier, The Journal of Supercritical Fluids, vol. 34, pp. 163-170, 2005.

[40] Susana P. Jesus, Renato Grimaldi, HaikoHense, "Recovery of $\gamma$-oryzanol from rice bran oil byproduct using supercritical fluid extraction", Elsevier, The Journal of Supercritical Fluids, vol. $55,149-155,2010$.

[41] Juliana M. Prado, Glaucia H. C. Prado, M. Angela. A. Meireles, "Scale-up study of supercritical fluid extraction process for clove and sugarcane residue", Elsevier, TheJournal of Supercritical Fluids, vol. 56, pp. 231-237, 2011.

[42] Juliana M. Prado, IredeDalmolin, Natália D. D. Carareto, Rodrigo C. Basso, Antonio J.A. Meirelles, J. Vladimir Oliveira, Eduardo A. C. Batista, M. Angela A. Meireles, "Sup ercritical fluid extraction of grape seed: Process scale-up, extract chemical composition and economic evaluation", Elsevier, The Journal of Food Engineering, vol. 109, pp. 249-257, 2012.

[43] Paulo T.V. Rosa, M.Angela A. Meireles, "Rapid estimation of the manufacturing cost of extracts obtained by supercritical fluid extraction", Elsevier, Journal of Food Engineering,vol. 67, pp. 235-240, 2005.

[44] Patrícia F. Leal, "Estudo comparativo entre os custos de manufatura e as propriedades funcionais de óleos voláteis obtidos por extração supercrítica e destilação por arraste a vapor”, Ph.D. Thesis, University of Campinas,Brazil, 2008. 